\title{
Anti-MUCl nano-aptamers for triple-negative breast cancer imaging by single-photon emission computed tomography in inducted animals: initial considerations
}

\author{
This article was published in the following Dove Press journal: \\ International Journal of Nanomedicine \\ 19 December 2016 \\ Number of times this article has been viewed
}

\author{
Fagner Santos do Carmo 1,2 \\ Eduardo Ricci-Junior ${ }^{3}$ \\ Cristal Cerqueira- \\ Coutinho ${ }^{4}$ \\ Marta de Souza Albernaz ${ }^{1,5}$ \\ Emerson Soares Bernardes ${ }^{6}$ \\ Sotiris Missailidis ${ }^{7}$ \\ Ralph Santos-Oliveira ${ }^{2}$ \\ 'Rio de Janeiro State University, \\ Biology Institute Roberto Alcantara \\ Gomes, ${ }^{2}$ Brazilian Nuclear Energy \\ Commission, Nuclear Engineering \\ Institute, ${ }^{3}$ Federal University of Rio de \\ Janeiro, Faculty of Pharmacy, ${ }^{4}$ Federal \\ University of Rio de Janeiro, Institute \\ of Macromolecules Eloisa Mano, \\ ${ }^{5}$ University Hospital Clementino \\ Fraga Filho, Federal University \\ of Rio de Janeiro, Rio de Janeiro, \\ ${ }^{6}$ Instituto de Pesquisas Energéticas e \\ Nucleares, Centro de Radiofarmácia \\ São Paulo, ${ }^{7}$ Institute of Technology \\ in Immunobiologics Bio-Manguinhos, \\ Oswaldo Cruz Foundation (Fiocruz), \\ Rio de Janeiro, Brazil
}

Correspondence: Ralph Santos-Oliveira Brazilian Nuclear Energy Commission, Nuclear Engineering Institute, R Helio de Almeida, 75 Illha do Fundão, Rio de Janeiro, Brazil

Tel +55 2l 21733964

Email presidenciaradiofarmacia@gmail. com

\begin{abstract}
The early and specific detection of tumors remains a barrier in oncology, especially in cases such as the triple-negative breast cancer (TNBC). To address this gap, aptamers have found an important application in the recognition of tumor biomarkers such as mucin 1 (MUC1). However, there are still some difficulties in the use of aptamer, as their rapid biological clearance makes their use as drugs limited. In this study, the anti-MUC1 aptamer was used as a drug delivery system (DDS) for a radioactive polymeric nanoparticle (NP) in the imaging of TNBCs. Thus, poly(lactic-co-glycolic acid) NPs loaded with the anti-MUC1 aptamer and labeled with technetium-99m were used for a biodistribution study and imaging of TNBC. The results confirmed that the NP was successfully obtained, with a mean size of $262 \mathrm{~nm}$, according to the dynamic light scattering data. The biodistribution assay in induced animal models with TNBC showed that although there was a high capture by intestine $(>30 \%)$, the DDS developed had a high tumor uptake $(5 \%)$ and with great in vivo imaging properties, corroborating the possibility of use of this DDS as an imaging drug for TNBC.
\end{abstract}

Keywords: aptamer, cancer control, imaging, nuclear medicine, radiopharmacy

\section{Introduction}

Breast cancer is one of the most common cancers and afflicts thousands of women worldwide. The incidence rates vary greatly worldwide, from 19.3 per 100,000 women in Eastern Africa to 89.7 per 100,000 women in Western Europe. In most of the developing regions, the incidence rates are $<40$ per 100,000 and it is estimated that over 508,000 women died in 2011 because of breast cancer, worldwide. ${ }^{1,2}$

Triple-negative breast cancer (TNBC) is characterized by a low expression of the estrogen receptor, progesterone receptor, and human epidermal growth factor receptor 2. TNBC tends to behave more aggressively than the other breast cancer subtypes (has rapid growth and higher chance of recurrence and metastasis). ${ }^{3,4}$ TNBC accounts for $\sim 20 \%$ of all breast cancers and is more frequently diagnosed in women aged $>40$ years and particularly of African descendancy. ${ }^{5-7}$ There is strong evidence that links TNBC with the mutation of $B R C A$ gene. ${ }^{8}$ The diagnosis of TNBC is currently performed using a microarray technique. ${ }^{9,10}$ However, both diagnosis and treatment remain a clinical challenge.

In recent years, TNBC has been linked to a specific immunologic response originating from the large expression of the mucin 1 (MUC1) gene. MUC 1 belongs 
to the family of genes that encodes transmembrane glycoproteins type I, with high molecular weight, ${ }^{11,12}$ and is present ubiquitously in the apical surface of glandular epithelial cells, including gastrointestinal, respiratory, urinary, and reproductive tract. ${ }^{12}$ Overexpression of MUC1 has been identified as a marker of malignancy in several primary tumors, such as breast, ovarian, colon, lung, gastric, pancreatic, and prostate cancers. ${ }^{11,13-17}$ Normal tissue and tumor have the same amino acid sequence, but only distinguished by MUC 1 overexpression by cancer cells and its aberrant glycosylation pattern. ${ }^{16}$

MUC1 has been the target for many therapeutic approaches, including antibodies, vaccine therapies, and aptamers. ${ }^{18,19}$ Aptamers are synthetic oligonucleotides, such as ribonucleic acid (RNA) and single-stranded deoxyribonucleic acid, which can bind to their targets with high affinity and specificity because of their specific secondary and tertiary structures. ${ }^{20}$ Compared with antibodies, they offer a great potential in targeting tumor markers like MUC1 because of their small size, lack of immunogenicity, and superior tumor penetration. ${ }^{21}$ In addition, they have been capable of detecting circulating MUC1 in sandwich enzyme-linked immunosorbent assays, improving current detection limits, ${ }^{19}$ and have been extensively studied as radiopharmaceuticals for their potential in gamma-camera and single-photon emission computed tomography (SPECT) imaging. ${ }^{21-23}$ Furthermore, they have been shown to be particularly promising agents in photodynamic therapy as phototoxic agents ${ }^{24}$ and delivery agents of standard chemotherapy such as doxorubicin. ${ }^{25}$ Finally, the MUC1 aptamers have been successfully used in nanoparticle (NP) formulation, described both from our own group ${ }^{26}$ for silica NPs and from a different group for liposomal formulation in conjunction with paclitaxel. ${ }^{27}$ The properties of high affinity and specificity toward their targets make aptamers the molecules of choice to be used as delivery agents. Aptamers can be designed as targeting ligands, ${ }^{20}$ with their properties modified at demand.

The use of nanotechnology in cancer treatment and diagnosis is rapidly evolving. In recent years, many research groups have been devoting their efforts to the development of NPs to interrogate specific molecular targets (imaging probes) and to deliver systemic radiotherapy to those targets, while minimizing the toxicity to normal cells, following what has been called the "magic bullet" concept. In this fashion, NPs conjugated with unstable radioisotopes for positron emission tomography and SPECT imaging have the highest potential for successful imaging because of their inherited high sensitivity. The same NPs can be conjugated with beta-minus- or alpha-particle-emitting radioisotopes for targeted radiotherapy. ${ }^{28-32}$ In this study, unique nanoradiopharmaceuticals with polymeric NPs of the anti-MUC-1 aptamer labeled with technetium-99m $\left({ }^{99 \mathrm{~m}} \mathrm{Tc}\right)$ were developed for the early diagnosis of MUC1 overexpression in TNBC. These novel imaging compounds have the potential to play an important role in the development of improved imaging strategies for TNBC.

\section{Methodology Aptamers}

The aptamers used in this study have been those previously described by Ferreira et $\mathrm{al}^{18}$ and used in various studies as radiopharmaceuticals alone or in multimeric and pegylated complexes. $^{21-23}$ These aptamers have been selected against the APDTRPAPG synthetic peptide of the MUC1 tandem repeat sequence using traditional SELEX approaches. The structure of this anti-MUC1 aptamer has also been studied by nuclear magnetic resonance ${ }^{33}$ and deposited in Protein Data Bank.

\section{Nanoparticles}

Two NPs were prepared: the first one empty (no anti-MUC1) and the second one with anti-MUC1 aptamer.

\section{Empty NP}

Thirty milligrams of poly (lactic acid-co-L-acid) (PLGA) was dissolved in $2 \mathrm{~mL}$ of $\mathrm{CH}_{2} \mathrm{Cl}_{2}$ (solution A). Then $1 \mathrm{~mL}$ of solution of polyvinyl alcohol (PVA) 5\% was dripped over solution $\mathrm{A}$ and then ultrasonicated by 2 cycles of 30 seconds in a potency of $55 \mathrm{~W}$, forming an emulsion (solution $\mathrm{B}$ ). The solution B was dropped into $40 \mathrm{~mL}$ of a solution of PVA $1 \%$ and ultrasonicated by 2 cycles of 30 seconds in a potency of $55 \mathrm{~W}$. The final product was a PLGA emulsion system oil-in-water-in-oil $(\mathrm{O} / \mathrm{W} / \mathrm{O})$. This final solution was dried under low pressure at room temperature for 40 minutes to eliminate the excess of dichloromethane.

\section{Loaded NP with aptamer anti-MUCI}

Thirty milligrams of PLGA was dissolved in $2 \mathrm{~mL}$ of $\mathrm{CH}_{2} \mathrm{Cl}_{2}$ (solution A). Then $1 \mathrm{~mL}$ of a solution of PVA 5\% and $100 \mu \mathrm{g}$ of anti-MUC-1 aptamer was dripped over the solution $A$ and then ultrasonicated in 2 cycles of 30 seconds with a potency of $55 \mathrm{~W}$, forming an emulsion (solution B). The solution B was dropped into $40 \mathrm{~mL}$ of a solution of PVA $1 \%$ and ultrasonicated in 2 cycles of 30 seconds with a potency of $55 \mathrm{~W}$. The final product was a PLGA emulsion system $\mathrm{O} / \mathrm{W} / \mathrm{O}$. This final solution was dried under lower pressure at room temperature for 40 minutes to eliminate the excess of dichloromethane (Scheme 1). 

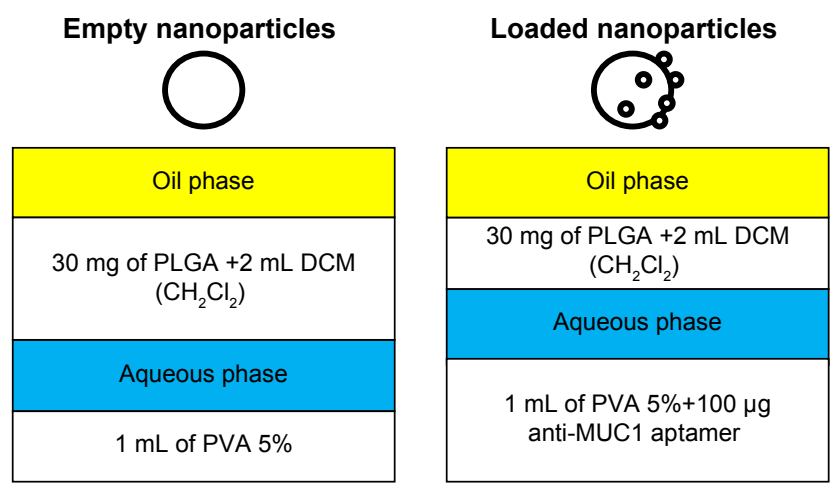

Scheme I Schematic process of the formation of nanoparticles. Abbreviations: DCM, dichloromethane; MUCI, mucin I; PLGA, poly(lactic-coglycolic acid); PVA, polyvinyl alcohol.

\section{Size determination by dynamic light scattering}

NP size distribution, mean size, and polydispersity index of the NPs were determined by dynamic light scattering (DLS) using the equipment Zetasizer Nano ZS (Malvern Instruments, Worcestershire, UK). The measurements were performed in triplicate at $25^{\circ} \mathrm{C}$, and the laser incidence angle in relation to the sample was $173^{\circ}$ using a $12 \mathrm{~mm}^{2}$ quartz cuvette. The mean \pm standard deviation was assessed.

\section{Labeling with ${ }^{99 m}$ Tc-nano- radiopharmaceuticals}

The method used was the direct labeling process as described by Sá et $\mathrm{al}^{26}$ and Albernaz et al. ${ }^{34}$ The labeling process used $150 \mu \mathrm{L}$ of NPs (empty and loaded), which were incubated with $\mathrm{SnCl}_{2}$ solution $(30 \mu \mathrm{L} / \mathrm{mL})$ (Sigma-Aldrich, St Louis, MO, USA) for 20 minutes at room temperature. Then this solution was incubated with $2 \mathrm{mCi}(\sim 300 \mu \mathrm{L})$ of ${ }^{99 \mathrm{~m}} \mathrm{Tc}$ (Instituto de Pesquisas Energeticas e Nucleares [IPEN/CNEN]) for 10 minutes, which labeled the NPs with ${ }^{99 \mathrm{~m}} \mathrm{Tc}$.

To characterize the labeled NPs (empty and loaded), paper chromatography was carried out using Whatman No 1 paper. The paper chromatography was performed using $2 \mu \mathrm{L}$ of the labeled NP in acetone (Sigma-Aldrich) as mobile phase. The radioactivity of the strips was verified in a gamma counter (Perkin Elmer Wizard ${ }^{\circledR}$ 2470, Perkin Elmer, Shelton, CT, USA). To confirm the efficacy of the labeling process of the NP (empty and loaded), paper chromatography was performed at 8 hours (Table 1).

\section{In vivo analysis}

\section{Tumor xenograft models}

MDA-MB-231 cells (American Type Culture Collection, Manassas, VALLC) were cultured in RPMI (Thermo Fisher Scientific, MA USA) supplemented with $10 \%$ of fetal bovine
Table I Efficacy of the labeling process with technetium-99m of the PLGA nanoparticles

\begin{tabular}{ll}
\hline Nanoparticle type & Efficacy of labeling at 8 hours \\
\hline PLGA-nanoparticle (empty) & $99.76 \pm 0.8$ \\
PLGA-aptamer-nanoparticle & $99.83 \pm 0.7$ \\
\hline
\end{tabular}

Abbreviation: PLGA, poly(lactic-co-glycolic acid).

serum (Gibco) and $50 \mu \mathrm{g} / \mathrm{mL}$ of gentamicin (Gibco). Mycoplasma contamination in cultured cells was excluded using Lonza Mycoplasma Detection Kit.

Tumors were established by subcutaneous (sc) injection of $2 \times 10^{6}$ MDA-MB-231 cells at the back of 6-week-old female $\mathrm{BALB} / \mathrm{c}$ nude mice. The tumor size was monitored for 3 weeks and measured by a caliper. The tumor size before imaging was about $2 \mathrm{~cm}$ in diameter. The BALB/c nude mice were bred at the animal facility of the Nuclear Energy Research Institute (IPEN). This study and the animal procedures were approved by the University of Pernabuco Ethics Committee, under the number: 23076020578201327. All animal experiments were done in accordance with the regulations and guidelines of Brazilian Law for animal experiments (Law number 11.794/2008 and Decree 6.899/2009). These mice were observed three times per week for evidence of distress, ascites, paralysis, or excessive weight loss.

\section{Biodistribution studies}

Evaluation of the biodistribution of NPs was performed using two groups: 1) control group using empty NPs (n=6) and 2) intervention group using NPs loaded with aptamer $(n=6)$, both labeled with ${ }^{99 \mathrm{~m}} \mathrm{Tc}$. The mice were anesthetized with mixed solution of $10 \%$ ketamine and $2 \%$ xylazine in a volume of $15 \mu \mathrm{L}$ and administered intramuscularly (thigh). The nano-radiopharmaceuticals (3.7 MBq in volume of $0.2 \mathrm{~mL}$ ) were administered retro-orbitally. ${ }^{34}$ Both groups were killed by asphyxiation using a carbon dioxide gas chamber after 2 hours (120 minutes) of radio-compound administration. Organs (brain, lungs, kidneys, stomach, small and large intestine, bladder, heart, and blood pool) were removed and weighted and the activity in each organ and blood was counted by a gamma counter (Perkin Elmer Wizard 2470). The results were expressed as uCiper organ. ${ }^{26,34}$

\section{SPECT imaging}

Planar images were obtained at 90 minutes after injection of nano-radiopharmaceuticals $(3.7 \mathrm{MBq}$ in volume of $0.2 \mathrm{~mL}$ ) using a Millenium Gamma Camera (GE Healthcare, Cleveland, OH, USA). Counts were acquired for 5 minutes in a $15 \%$ window centered at $140 \mathrm{keV}$. The images were processed using OsiriXsoftware, and regions of interest 
(ROIs) over the tumor were selected for specific analysis. Three induced mice were imaged separately.

\section{Results and discussion DLS size characterization}

Figure 1 shows the mean size and size distribution of the NPs (empty and loaded). According to the distribution profile it is possible to infer that NPs presented a monomodal size distribution, with a mean size of $255 \mathrm{~nm}$ for the empty NPs and $262 \mathrm{~nm}$ for the aptamer-NPs. These results were not statistically different when comparing the two NPs, indicating that there is a slight increase in size for the NP containing the aptamer on its surface. However, as the aptamer is a small molecule it does not seem to increase greatly the size of the polymer NP (aptamers have a molecular weight ranging from 5 to $15 \mathrm{kDa}$ ). Narrow peaks suggested homogeneous systems with sizes near to the mean.

\section{Labeling process}

All the PLGA NPs using 1) empty and 2) aptamer-loaded antiMUC1 were successfully labeled with ${ }^{99 \mathrm{~m}} \mathrm{Tc}$. The average of labeling efficacy was over $97 \%$ in all cases.

\section{Tumor xenograft model}

After 3 weeks of the sc injection of $2 \times 10^{6}$ MDA-MB-231 cells the tumor was palpable and visible as in Figure 2.

\section{Biodistribution study} NP loaded with anti-MUCI aptamer

The biodistribution data (Figure 3) demonstrated that the nano-aptamer has a high hydrophilicity, and for that reason

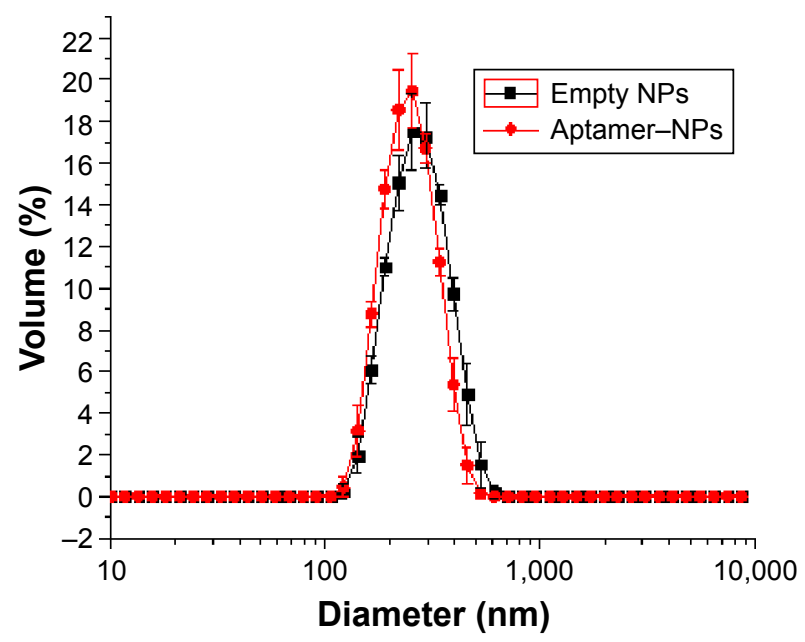

Figure I Mean size and size distribution of the nanoparticles.

Notes: The empty NPs are in black and the aptamer-NPs are in red. Analyses were performed at $25^{\circ} \mathrm{C}$ after preparation. Error bars indicate standard deviation for the triplicates.

Abbreviation: NPs, nanoparticles. has a high uptake by the kidneys ( $\sum$ Kidneys $\left.0.4131 \mu \mathrm{Ci}\right)$. It means that $48.43 \%$ of the nano-radiopharmaceuticals were in the kidneys. This is important for two reasons. First, it demonstrates the renal clearance of the nano-radiopharmaceutical, which is a desirable property. Second, the reabsorption mechanism present in the kidneys will probably help the biodistribution of the NP in the whole body. ${ }^{35,36}$

The presence of MUC1 in the intestines (large and small) $)^{37,38}$ may, in some cases, interfere in the biodistribution of the nano-aptamer labeled with ${ }^{99 \mathrm{~m}} \mathrm{Tc}$, because it is a pan-epithelial mucin. ${ }^{39-41}$ In this case, the nano-aptamer labeled with ${ }^{99 \mathrm{~m}} \mathrm{Tc}$ showed an uptake of $16.71 \%$ in the large intestine $(0.13753 \mu \mathrm{Ci})$ and $19.65 \%$ in the small intestine $(0.16172 \mu \mathrm{Ci})$. Furthermore, the size of the nano-aptamer labeled with ${ }^{99 \mathrm{~m}} \mathrm{Tc}$ may interfere in the biodistribution, because it may be trapped into the intestinal microvilli because of its higher irrigation. However, as the labeled empty NP had a lower intestine uptake, this seems a less plausible explanation, indicating a potential interaction of the MUC1 aptamer (see the following text and Figure 4).

NPs suffer from the limitation of rapid clearance by the mononuclear phagocytic system (MPS) located primarily in the liver and spleen, thereby limiting the dose available for the disease site. ${ }^{42,43}$ In this particular case the spleen uptake was very low $(0.01504 \mu \mathrm{Ci})$ representing $1.82 \%$ of the total dose. The use of PLGA NP has demonstrated lower uptake by the spleen, and, thus, an advantage in the use of this NP. In addition, the presence in the liver was also low. The total amount was $0.11917 \mu \mathrm{Ci}$, representing $14.48 \%$ of the total nano-aptamer labeled with ${ }^{99 \mathrm{~m}} \mathrm{Tc}$, less than the uptake by the intestines, also representing an advantage of this NP system.

The uptake by the lesion (tumor) showed a value of $0.0499 \mu \mathrm{Ci}(5 \%)$ of the nano-aptamer labeled with ${ }^{99 \mathrm{~m}} \mathrm{Tc}$, which supports the use of the nano-aptamer as an imaging agent, also corroborating the imaging results. Is is important to notice that the uptake in the brain is negligible.

\section{Empty NP}

The results of the biodistribution of the empty NP (Figure 4) showed renal clearance with a total of $77 \%$ of the empty NP uptake by the kidneys ( $\sum$ Kidneys $1.9627 \mu \mathrm{Ci}$ ).

The presence of MUC1 in the intestines did not interfere in the biodistribution of the empty NP, as expected. The values in the large intestine $(0.7 \%)$ and small intestine $(1.66 \%)$ were quite different from that observed in the loaded NP, showing that the presence of the aptamer in the NP was continuous throughout the biodistribution test. 

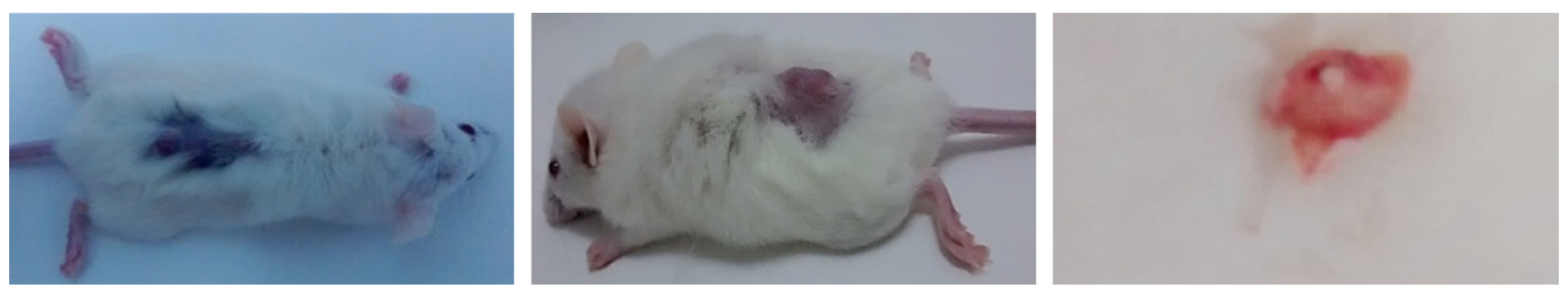

Figure 2 Tumor growth after 3 weeks of injection of $2 \times 10^{6}$ MDA-MB-23I cells in the back dorsal region of mice.

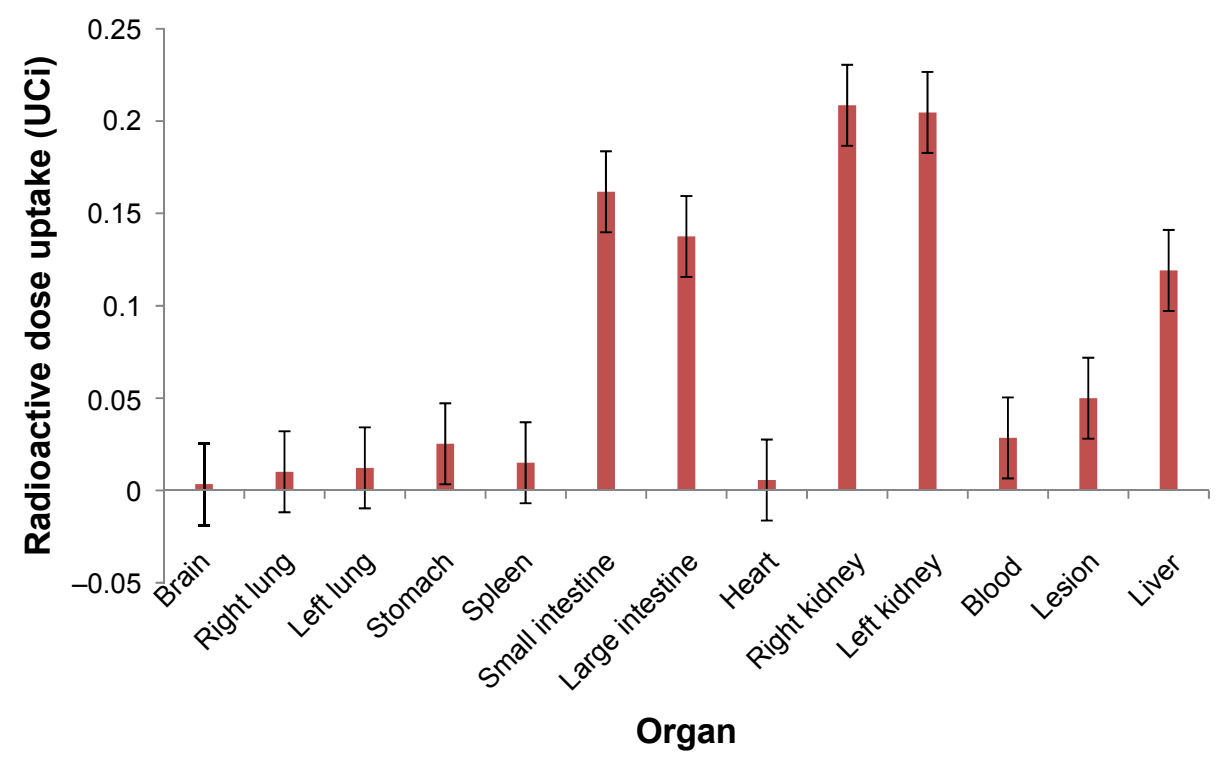

Figure 3 Biodistribution of loaded nanoparticle in induced mice.

Note: Error bars were calculated using the mean \pm standard deviation.

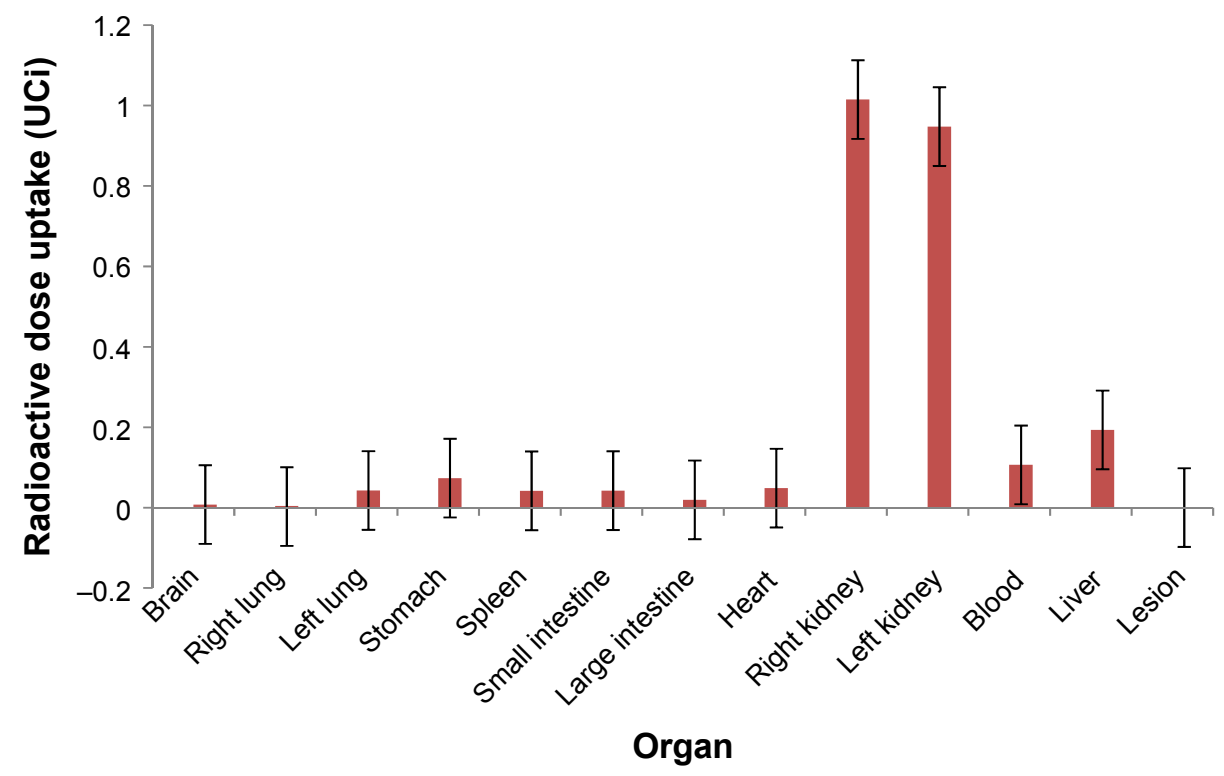

Figure 4 Biodistribution of empty nanoparticle in induced mice. 


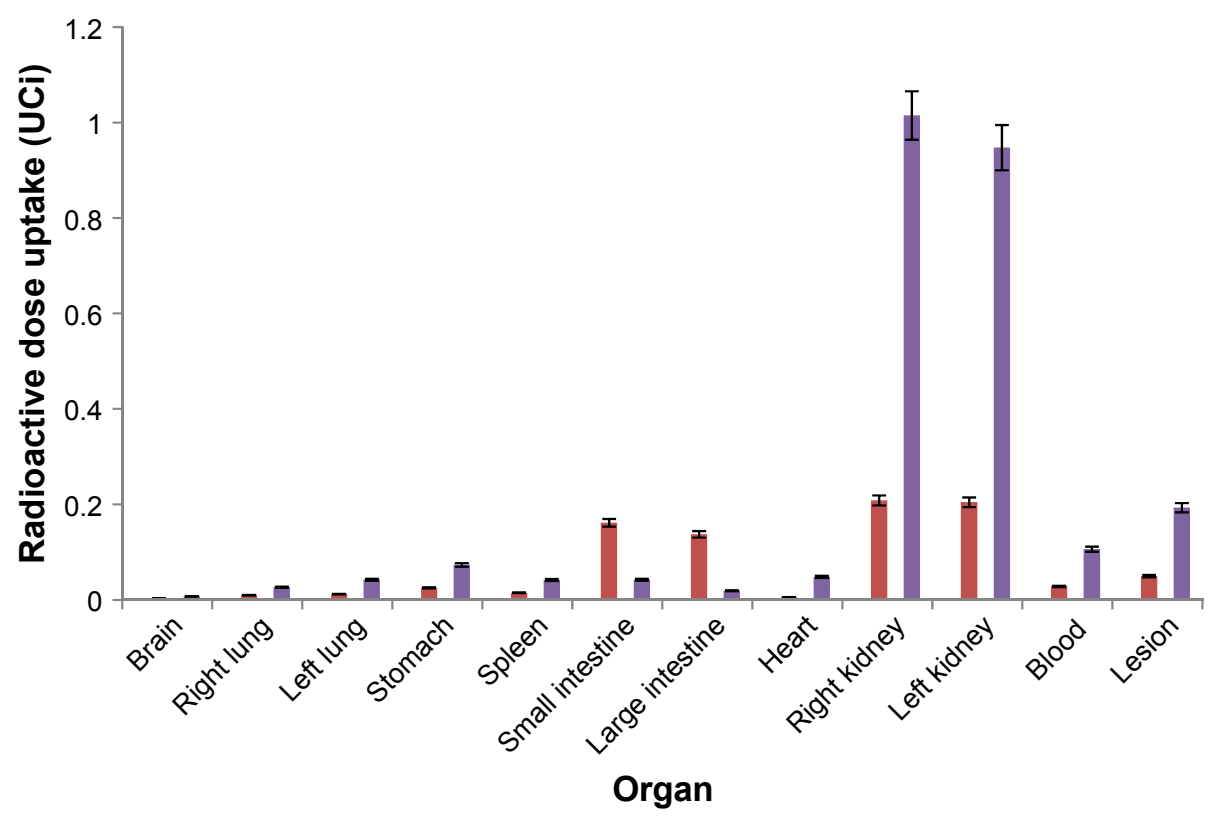

Figure 5 Comparison of biodistribution of empty (purple) and loaded (red) nanoparticle in inducted mice.

The small amount of NP in the stomach $(0.07351 \mu \mathrm{Ci})$ demonstrated no formation of colloid with the ${ }^{99 \mathrm{~m}} \mathrm{Tc}$. It is important to note the presence of higher amount in spleen $(0.04189 \mu \mathrm{Ci} ; 1.6 \%)$ and liver $(0.1933 \mu \mathrm{Ci} ; 7.6 \%)$, showing that the empty NP is taken up by the MPS, although in low concentrations. These data are important because, when comparing with the loaded NP, the uptake by the spleen is the same; however, the uptake by the liver is twice as much in the loaded NP. This means that the presence of the anti-MUC1 aptamer in the NP stimulates the MPS, especially in the liver. There was no uptake by the empty NP by the lesion. The amounts in brain, blood, and other organs are negligible.

To better understand the results of both graphics, they are shown together (Figure 5). It is possible to observe the higher uptake by the lesion and the better renal clearance by the drug delivery system.

\section{SPECT imaging}

In the SPECT (Figure 6) it is possible to observe the higher uptake in the lesion area. The ROI showed that the increased uptake region (yellow) was because of the biodirection of the anti-Muc1 aptamer NP accumulation. It is also possible to observe the kidney uptake in the image (lower region), corroborating the biodistribution result. The increased uptake region is because of the retro-orbital injection and is the remaining radioactivity in the injection site. The imaging findings, together with the results from the biodistribution assay, confirm the possible use of this $\mathrm{NP}$ as an imaging agent.

\section{Conclusion}

The results confirmed that the nano-radiopharmaceuticals based on the anti-MUC1 aptamer could be used as an imaging agent for TNBC. The results of the biodistribution study aligned with the SPECT imaging results, suggesting that this drug delivery system may represent a safe and alternative agent for the TNBC. The renal clearance and the low uptake

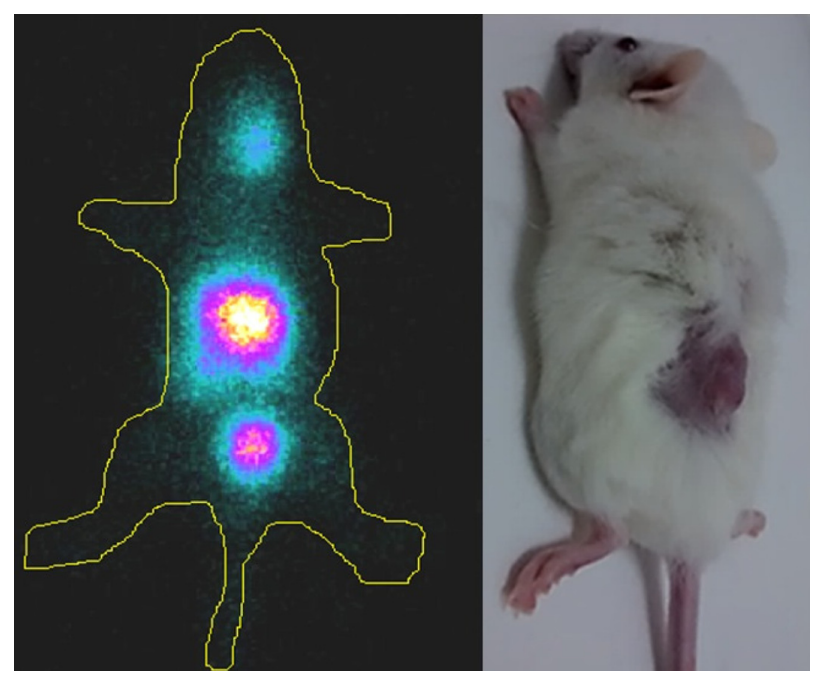

Figure 6 Scintigraphy of anti-MUCI nano-aptamer in animals induced with triplenegative breast cancer.

Abbreviation: $\mathrm{MUCl}$, mucin I. 
by the liver and spleen suggest its potential application in human beings.

\section{Disclosure}

The authors report no conflicts of interest in this work.

\section{References}

1. GLOBOCAN 2012: cancer incidence and mortality worldwide in 2012 - IARC; 2012. Available from: http://globocan.iarc.fr/Pages/ fact_sheets_population.aspx. Accessed October 10, 2016.

2. Chappuis P, Rosenblatt J, Foulkes W. The influence of familial and hereditary factors on the prognosis of breast cancer. Ann Oncol. 1999; 10(10):1163-1170.

3. Sorlie T. Molecular portraits of breast cancer: tumors subtypes as distinct disease entities. Eur J Cancer. 2004;40(18):2667-2675.

4. Jemal A, Center MM, Ward E, Thun MJ. Cancer occurrence. Methods Mol Biol. 2009;471:3-29.

5. Carey LA, Perou CM, Livasy CA. Race, breast cancer subtypes, and survival in the Carolina Breast Cancer Study. JAMA. 2006;295(21): 2492-502.

6. Reis-Filho JS, Westbury C, Pierga JY. The impact of expression, profiling on prognostic and predictive testing in breast cancer. J Clin Pathol. 2006;59(3):225-231.

7. DeSantis C, Ma J, Bryan L, Jemal A. Breast cancer statistics, 2013. CA Cancer J Clin. 2014;64(1):52-62.

8. Chabalier C, Lamare C, Racca C, Privat M, Valette A, Larminat F. BRCA1 down regulation leads to premature inactivation of spindle checkpoint and confers paclitaxel resistance. Cell Cycle. 2006;5(9): 1001-1007.

9. Jeffrey SS, Fero MJ, Børresen-Dale AL, Botstein D. Expression array technology in the diagnosis and treatment of breast cancer. Mol Interv. 2002;2(2):101-109.

10. Dong M, How T, Kirkbride KC, et al. The type IIITGF- $\beta$ receptor suppresses breast cancer progression. J Clin Invest. 2007;117:206-217.

11. Gender SJ, Spicer AP. Epithelial mucin genes. Annu Rev Physiol. 1995; 57:607-634.

12. Gender SJ. MUC1, the renaissance molecule. J Mammary Gland Biol Neoplasia. 2001;6(3):339-353.

13. Girling A, Bartkova J, Burchell J, Gendler S, Gillett C, TaylorPapadimitriou J. A core protein epitope of the polymorphic epithelial mucin detected by the monoclonal antibody SM-3 is selectively exposed in a range of primary carcinomas. Int $J$ Cancer. 1989;43(6):1072-1076.

14. Ho SB, Niehans GA, Lyftogt C, et al. Heterogeneity of mucin gene expression in normal and neoplastic tissues. Cancer Res. 1993;53: 641-651.

15. Zhang YM, Liu N, Zhu ZH, Rusckowski M, Hnatowich DJ. Influence of different chelators (HYNIC, MAG3 and DTPA) on tumor cell accumulation and mouse biodistribution of technetium- $99 \mathrm{~m}$ labeled antisense DNA. Eur J Nucl Med. 2000;27(11):1700-1707.

16. Taylor-PapadimitriouJ, Burchell J, Miles DW, Dalziel M. MUC1 and cancer. Biochim. Biophys. Acta. 1999;1455(2-3):301-313.

17. Vlad AM, Diaconu I, Gantt KR. MUC1 in endometriosis and ovarian cancer. Immunol Res. 2006;36(1-3):229-236.

18. Ferreira CSM, Matthews C, Missailidis S. DNA aptamers that bind to Muc1 tumour marker: design and characterization of Muc1-binding single stranded DNA aptamers. Tumour Biol. 2006;27(6):289-301.

19. Ferreira CSM, Papamichael K, Guilbault G, Schwarzacher T, Gariepy J, Missailidis S. DNA aptamers against Muc1: design of aptamer-antibody sandwich ELISA for early tumour diagnosis. Anal Bioanal Chem. 2008; 390(4):1618-2642.

20. Chopra A, Shukla R, Sharma TK. Aptamers as an emerging player in biology. Aptamers Syn Antibodies. 2014;1(1):1-11.
21. Borbas KE, Ferreira CS, Perkins A, Bruce JI, Missailidis S. Design and synthesis of mono- and multimeric targeted radiopharmaceuticals based on novel cyclen ligands coupled to anti-MUC1 aptamers for the diagnostic imaging and targeted radiotherapy of cancer. Bioconjug Chem. 2007;18(4):1205-1212.

22. Pieve CD, Perkins AC, Missailidis S. Anti-Muc1 aptamers: radiolabelling with $(99 \mathrm{~m}) \mathrm{Tc}$ and biodistribution in Mcf-7 tumour-bearing mice. Nucl Med Biol. 2009;36(6):703-710.

23. Da Pieve C, Blackshaw E, Missailidis S, Perkins AC. PEGylation and biodistribution of an anti-MUC1 aptamer in MCF-7 tumor-bearing mice. Bioconjug Chem. 2012;23(7):1377-1381.

24. Ferreira CS, Cheung MC, Missailidis S, Bisland S, Gariépy J. Phototoxic aptamers selectively enter and kill epithelial cancer cells. Nucleic Acids Res. 2009;37(3):866-876.

25. Hu Y, Duan J, Zhan Q, Wang F, Lu X, Yang XD. Novel MUC1 aptamer selectively delivers cytotoxic agent to cancer cells in vitro. PLoS One. 2012;7(2):e31970.

26. Sá LT, Simmons S, Missailidis S, da Silva MI, Santos-Oliveira R. Aptamer-based nanoparticles for cancer targeting. J Drug Target. 2013; 21(5):427-434.

27. Yu C, Hu Y, Duan J, et al. Novel aptamer-nanoparticle bioconjugates enhances delivery of anticancer drug to MUC1-positive cancer cells in vitro. PloS One. 2011;6:e24077.

28. Hamoudeh M, Kamleh MA, Diab R, Fessi H. Radionuclides delivery systems for nuclear imaging and radiotherapy of cancer. Adv Drug Deliv Rev. 2008;60:(12)1329-1346.

29. RobilottaCecil C. A tomografia por emisş̧ao de pósitrons: uma nova modalidade na medicina nuclear brasileira. Ver Panam Salud Publica [Positron emission tomography: a new modality in Brazilian nuclear medicine]. V 20, n. 2/3; 2006. Available from: http://journal.paho.org/ uploads/1162234592.pdf. Acesso em 05 de março de 2016. Portuguese.

30. Tonin RS. Cintilografia e PET/CT nas neoplasias malignas [Scintigraphy and PET/CT in malignant neoplasms]. Porto Alegre, Rio Grande do Sul: UFRS; 2011. Portuguese.

31. Santos-Oliveira R. Nanoradiopharmaceuticals: is that the future for nuclear medicine? Curr Radiopharm. 2011;4(2):140-143.

32. Sarcinelli MA. Desenvolvimento de Nanopartícula de Poli(Ácido Lático) contendo Anticorpo Monoclonal marcada com $99 \mathrm{mTc}$ para o Diagnóstico Precoce e Tratamento Eficaz do Câncer de Mama [Tese de D.Sc]. Rio de Janeiro, RJ: IMA/UFRJ; 2014. Portuguese.

33. Albernaz M de S, Ospina CA, Rossi AM, Santos-Oliveira R. Radiolabelled nano hydroxyapatite with $99 \mathrm{mTc}$ : perspectives to nano radiopharmaceuticals construction. Artif Cells Nanomed Biotechnol. 2014;42(2):88-91.

34. Pinto SR, Sarcinelle MA, de Souza Albernaz M, et al. In vivo studies: comparing the administration via and the impact on the biodistribution of radiopharmaceuticals. Nucl Med Biol. 2014;41(9):772-774.

35. Zhou J, Satheesan S, Li H, et al. Cell-specific RNA aptamer against human CCR5 specifically targets HIV-1 susceptible cells and inhibits HIV-1 infectivity. Chem Biol. 2015;22(3):379-390.

36. Baek JS, Kim JH, Park JS, Cho CW. Modification of paclitaxel-loaded solid lipid nanoparticles with 2-hydroxypropyl-b-ciclodextrin enhances absorption and reduces nephrotoxicity associated with intravenous injection. Int J Nanomedicine. 2015;10:5397-5405.

37. Xu F, Liu F, Zhao H, An G, Feng G. Prognostic significance of MUC1 in various human epithelial cancer: a meta-analysis. Medicine. 2015;94(50): e2286.

38. Gouyer V, Dubuquoy L, Robbe-Masselot C, et al. Delivery of a mucin domain enriched in cysteine residues strengthens the intestinal mucous barrier. Sci Rep. 2015;15(5):9577.

39. Kim GE, Bae HI, Park HU, et al. Aberrant expression of MUC5AC and MUC6 gastric mucins and sialylTn antigen in intraepithelial neoplasm of the pancreas. Gastroenterology. 2002;123(4):1052-1060.

40. Corfield A, Myerscough N, Longman R, Sylvester P, Arul S, Pignatelli M. Mucins and mucosal protection in the gastrointestinal tract: news prospects for mucins in the phatology of gastrointestinal disease. Gut. 2000;47(4):589-594. 
41. Lee MJ, Lee HS, Kim WH, Choi Y, Yang M. Expression of mucins and cytokeratins in primary carcinomas of the digestive system. Mod Pathol. 2003;16(5):403-410.

42. Anselmo AC, Gupta V, Zern BJ, et al. Delivering nanoparticles to lungs while avoiding liver and spleen through adsorption on red blood cells. ACS Nano. 2013;7(12):11129-11137.
43. Blanco E, Shen H, Ferrari M. Nanoparticle rational design implementation for overcoming delivery barriers. Nat Biotechnol. 2015;33: 941-951.

\section{Publish your work in this journal}

The International Journal of Nanomedicine is an international, peerreviewed journal focusing on the application of nanotechnology in diagnostics, therapeutics, and drug delivery systems throughout the biomedical field. This journal is indexed on PubMed Central,

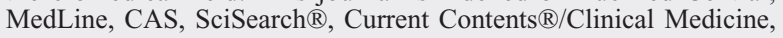

Journal Citation Reports/Science Edition, EMBase, Scopus and the Elsevier Bibliographic databases. The manuscript management system is completely online and includes a very quick and fair peer-review system, which is all easy to use. Visit http://www.dovepress.com/ testimonials.php to read real quotes from published authors.

Submit your manuscript here: http://www.dovepress.com/international-journal-of-nanomedicine-journal 